\title{
Medical Geography in Egypt: As an Interdisciplinary Subfield
}

\author{
Mohamed Nour Eldin Ibrahim Elsabawy
}

\author{
Professor of Medical Geography \\ Faculty of Arts, Minia University, \\ Minia , Egypt.
}

\section{Doi:10.5901/jesr.2013.v3n5p109}

\section{Introduction}

Medical geography studies geographical factors concerned with cause and effect of health and disease. So its task not to study diseases only, but places affected with such maladies, and not studies health only but Areal differentiations in health Care patterns.

This paper aims to study the importance of medical geography as an interdisciplinary subdiscipline or subfield in Human and Social geography and attempt to follow up, analyze and classify studies of Medical geography in Egypt, since the existence of that branch in the beginning of 1980s to 2010 , to observe the development of these studies. This development undoubtedly is necessary because the concept, terrain, and the range of this subfield were not understandable in the beginning of studies. So, many researchers preferred choosing general topics in the first time. Gradually, they have been concentrating, deliberating on subjects related to some diseases which correlate to Egyptian geographical environment. Explicitly, we can decide that the studies of medical geography in Egypt seem to be more general and more comprehensive especially in the period from 1986 until 1996. Thereafter till 2010, studies have dealt with specific topics and new methods and materials of Medical Geography.

Medical Geography as a subfield depending upon many systems, polices and Sciences e.g. medicine, engineering, soil, Geology, Biology, Economy, Politics, History, and psychology. Etc. The main approaches of medical geography depends upon many trends and attitudes, the first approach called "disease diffusion", which differ from site to site as a cause of climatic factors e.g. temperature, humidity, winds, relief and topography, and other human causes. The second approach "Disease pattern", includes endemic, epidemic and pandemic diseases in micro and macro scale in the world, and studies spatial and areal differentiations. The third approach "Medical cartography" devoted to the distribution of diseases and health services, by using GIS and other advanced techniques. Mapping plays a crucial role in the history of medical geography literature, when physicians started to study and draw maps firstly. It was created to show historic outbreaks of diseases like Cholera in Broad Street, London 1835, then global influenza pandemic 1918, and Cholera epidemic in Egypt 1947, for example. The fourth approach "Ethno medicine and medical pluralism" which covers integration between traditional and modern medicine, in this context medical geography concentrates upon spatial variations between rural and urban behavior of the population, The fifth approach "Health care" which deals with planning health systems in different states. So such analysis should be done with the assistance of equations and mathematical methods such as gravity model, neighborhood analysis, and weight mean centers. The Sixth approach "Nutritional geography" which deals with the study of deprivation and hungry places, poverty zones, and through distribution of calories intake between human groups. The seventh approach "Associative relatives" which deals with statistical analysis using advanced indices such as factor analysis, correlation coefficient, standard deviations, analysis of variance and prediction measurements in health care and disease. 
Medical Geography is an important field because it aims to provide spatial understanding of health problems and improving health care systems worldwide, this sub-discipline has relatively a modern history though Hippocrates (5th-4th centuries BCE), and Arab physicians (Ibn Seena) investigated such topics which may fall in the area of medical geography. Although medical geography is eminent field of study today, geographers have some barriers to overcome when obtaining data. The problem is associated with recording a disease's locations. Most of underdeveloped countries don't have systematic medical registrations to enable medical geographers actually make a proper geographical analysis.

Medical geography as a science succeeds to put its foot on the geographic departments in Egyptian universities. This subtitle has become a learning subject in undergraduate and postgraduate courses in many universities in Egypt. Despite that has been emerged late in Egypt, compared to developed countries, it has found a good site among other geographic branches in a few years.

This paper may help new descendants in the geography departments, to know more about medical geography studies in Egypt in the past three decades, our problems and may anticipate solving them. Through co-operation between the geography departments in the Egyptian universities, and another departments of geography in African universities especially in Nigeria we can put strategic plan to covering all of regions according to the site, location and geographic sphere of every university in order to study health problems of population in provinces or states. Moreover, drawing a health map or disease map to each governorate or state, can help the decision maker and policies planners. Through a general strategy of the Ministries of Health and WHO we hope to eradicate serious diseases.

Although this study is interested in the Egyptian geographers studies in the field of medical geography, it can't neglect in the same time the contributions of physicians and scientists in the medical system in this field, which help geographers in their studies and papers.

\section{Pre- emerging of medical geography}

Physicians and scientists in research centers began to study geographical environment and its relationship with disease diffusion in Egypt before emerging expression of medical geography in Egypt many decades ago by medical geographers. Scientists and physicians help geographers to know more about the relationship between disease and the geographical environment, especially the epidemiologists, tropical medicine physicians and public health doctors.

These centers such as National Research Center, Theodore Bilhars institute, nutrition institute, Tropical medicine center, Cancer institute center, College of medicines, and other centers of research and treatment have many of specific scientific journals interested in disease of geographic environment. Geographers take a benefit of these journals in order to understand the disease pattern, disease diffusion, and the impact of geographical environment on the health and disease. Many of these journals deal with this relationship.

Although most of these papers which published in medical journals in the past fifty years were basically for physicians works and for medical purposes, but some papers were interested in social and geographical environment, when the epidemics and endemic diseases were widespread like Plague, Leprosy, Tuberculosis, Malaria, Trachoma, and other series diseases infected many thousands of Egyptian people. This relationship between geography and medicine reflected on the pattern of papers covered disease ecology, and the environment of these diseases which appeared and disappeared throughout the last century.

In this review, we spotlight only on sample papers related to geographical environment which published in these journals by physicians. One of them published by Ayad, N.A, under the title of "Short review of the epidemiology of schistosomiasis in Africa, Egypt."in the J ournal of Bilharsiasis., Vol.1.,1974. Another paper was published in the Egyptian journal of bilharzias in 1975 by AbuElhassan under the title of "Belharsiasis disease in the New Valley and in the reclamed coastal 
zone. In the Journal of tropical medicine and hygiene, vol.31. 1982., Mobarak published his paper under the title of "The schistosomiasis problem in Egypt"

Some papers studied the fishermen in the lakes, like the paper which was published in 1978 in the journal of bilharziasis under the title of "prevalence of schistosomiasis among fishermen of lake Maryut, Egypt by Ahmed,M.,Et al , and a recent paper in 2000 by Hammam M.H,and others in the American journal tropical medicine and hygiene 62, under the title of "The epidemiology of schistosomiasis in Egypt: Qena Governorate. Some other papers deal with "the effect of the irrigation systems in the prevalence of endemic disease, the Aswan high dam was a topic of one study about the prevalence of bilharzias by Malek,E.A. published in Egyptian Bilharsial journal, vol 8, 1981.

All of these papers did not only study the patient and the effect of irrigation systems in the morbidity level, but also extended to study the environment of intermediate host, as a part of circle of disease. El-Emam M. published his paper 1981 in the Egyptian journal of Bilharzias under the title of "Environmental study on the snail of Bilharzias in some zones in Arab Rebublic of Egypt" Another study for Mousa and Alhassan in 1972 about "The effect of water temperature on the snail intermediate hosts of Schistosomiasis in Egypt" published in Med. Assoc. vol.55,1972..Another study of Allam 1981 about "The effect of environmental factors on the prevalence of pure Schistosoma haematobium infection under basin and perennial irrigation systems in Upper Egypt" in Assiut Med Journal 1981., Abdel Wahab and others published paper in American Journal of tropical medicine \& hygiene., vol. 29,1980 under the title of "Schistosomiasis Mansoni in an Egyptian village in the Nile delta". "Abdel-Aty, M.A and others study in 1993 the same species of bilharsia but in Assuit province which situated in middle Egypt. Many papers covered field work studies like Trachoma Disease which spread between school pupils, one of this papers by Habib,M., and others about 'Prevalence of Trachoma in school children in a village in the Qalyub area of Egypt'. Another study for Mikhail,B., and others published in 1989 about "Impact of Beliefs about eye disease and trachoma in an Egyptian Delta" in the Bulletin of the High Institute of Public Health, vol.19, .1989..

Physicians studied the change of disease patterns before geographers in Egypt, one of these studies was introduced by Abd Elwahab about " Changing pattern of Schistosomiasis in Egypt 1935$1979^{\prime \prime}$ in tropical. medicine \& hygiene Journal., .On the other hand, physicians involved in study of the geographical and social environment of patient suffering from cancer. Elgazayerli, M.\& Aziz published this study in Breast Journal. of cancer.,1963, vol.17, they studied "The impact of Schistosoma infection on the breast cancer between males, perhaps this study is seemed as strange, but it is a scientific study. In 1981 Ibrahim studied "The distribution of cancer in Egypt twelve years experience (1970-1981)".

All these studies represent a small sample of physicians' studies, which covered stage of pre medical geography emerging in Egypt by Egyptian geographers. Before we turn over this review, we must no forget the role of two Egyptian physician scientists in this field, the first one is Abd-Elrahim Omran Professor of Epidemiology, University of North Carolina, and his theory which is known as Epidemiological transition. This theory helps to know more about the development of health societies, and it was applied on developing and underdeveloping countries. The second scientist is Yassen abd-Elghaffar Professor of liver diseases, in Cairo University, who realized the true importance of liver diseases problem in Egypt in the last decade of twentieth Century. He was aware of this dangerous disease and he predicted the disease development in the future, as a big health problem in Egypt.

\section{The emerging of medical geography in Egypt}

Papers and studies of physicians were indeed a green light to geographers to initiate medical geography studies in Egypt. The first article carries the title of medical geography by Egyptian geographer was in 1979, by Abu-Aianah,F. who published his paper under the title of "some 
aspects of infant mortality in Alexandria Egypt: A study in Medical Geography" in the Genus bulletin.

The second study in this field was in 1983, in the geography Department, Minia University. under the title of Kafr Elsheikh Governorate: A study in geography of disease ${ }^{1}$.

The progress of studies in the first years of 1980s was slow, because no one had an idea about this new branch. Gradually the studies have been growing up and have become widespread.

\section{The development of medical Geography in Egypt}

The development of any science, should pass through many stages, like living things, the first is the infancy, then maturity, and then the old, if science is succeeds to develop, it will live and grow, or vice versa.

Medical geography in Egypt as a subfield in geography science is relatively recent if we compare it with some other subfields. We can consider this subfield in the born stage. There are many evidences for that. The first one is the number of researchers in medical geography is still a few. The second one is that the number of studies and papers in medical geography is also little. The third is that the convenience of government and management with the importance of medical geographers in health planning needs support. They need to know that the experts and planners in the developing countries prefer choosing the geographer as a consultant to put health care plans on the geographical bases.

In spite of that, we can say medical geography studies developed in Egypt from 1979 to 2010. This development is not only in the number of studies and papers, but also in the branches, specific topics, and trends. We can divide study of Medical geography to three stages or three decades. The first one started from 1979 to 1989, the number of studies in this period was 7 only, because this branch was born few years ago, and the concepts of study is was not clear to geographers So most of the studies were under the title of medical geography, an applied study in general. There are no papers or studies written in Arabic and the libraries do not contain new journals like Social Science and Medicine, or some specific periodicals related to this branch, in addition to lack of global information systems networks, which were not known at that time.So researchers were suffering from lack of information and data so much. The second stage was from 1989: 1999, the number of studies is grows up to 18 studies. Most of papers and studies take specific subjects, either in the study of disease pattern or through following methods and new materials of medical geography study, like health services, mapping, and associative relations.

From 1999 to 2008 this number has increased to 30 studies, most of papers and studies are interested in the study of health care and health problems which Egyptian people suffer from. The general trend of papers in that decade studied problems of peoples like liver diseases, Kidney failure, respiratory, cancer, malaria, cardiovascular in Egypt or on the narrow scale .table 1 and figure 1 is show this development.

\footnotetext{
${ }^{1}$ in the early days of 1980, I was undergraduate student in final year of the university, when I visit some famous old bookstores in Cairo city "Alazbakia wall" I found a book with the title of "The Ecology of human Disease", the author is Jacques May., in this time I have not read any thing about medical geography, and I haven't any idea about this branch. The surprise that the author of this book dedicated his book to Abd-Elrahim Omran, at this time I did not know about Omran and May any thing. I read some chapters of this book during my serve in the Egyptian Army, when I finished this year in April 1982, I returned back to my college, as a demonstrator in the Geography Department. I joined to pre master degree in September 1982. Professor. Dr Yousry Elgowhary was a chair of Geography Department at that time. He usually chose a paper to every one of graduates to study, I was one of Eleven graduates in the class, when he try to chose my topic, I told him that I had a new topic in the branch of medical geography, "Geography of disease", he was surprised and asked me: "what is the meaning of Medical Geography. "? I responded. Then he accepted immediately, I finished my paper in the end of 1983, and I registered my Master thesis in 1984.
} 
Table 1: The development of medical geography studies in Egypt

\begin{tabular}{|c|c|c|}
\hline $\begin{array}{c}\text { Number of studies } \\
1979: \mathbf{1 9 8 9}\end{array}$ & $\begin{array}{c}\text { Number of studies } \\
\mathbf{1 9 8 9}: \mathbf{1 9 9 9}\end{array}$ & $\begin{array}{c}\text { Number of studies } \\
\mathbf{1 9 9 9}: \mathbf{2 0 0 8}\end{array}$ \\
\hline 7 & 18 & 30 \\
\hline
\end{tabular}

Fig. 1. The development of medical geography studies in Egypt

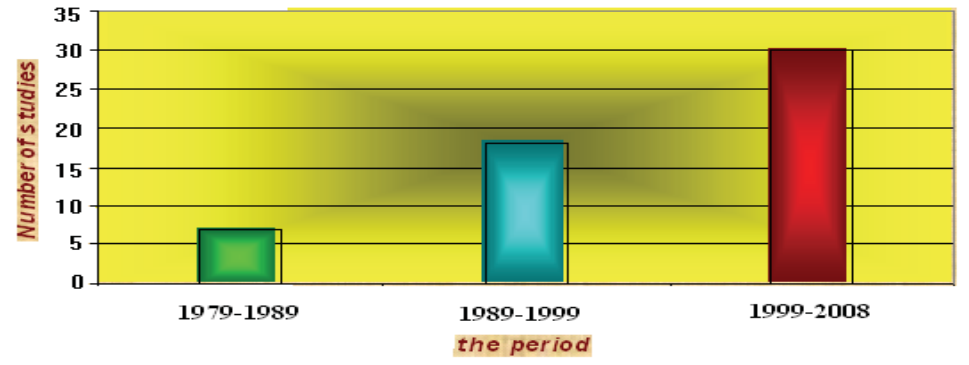

\section{Classification of medical Geography studies in Egypt}

We can classify the study of medical geography to some criteria as shown:-

\subsection{Subject of study}

The studies of medical geography in Egypt according to subjects can be divided into some topics as shown in table 2 and figure 2

Table 2: Classification of medical geography studies in Egypt according to subject

\begin{tabular}{|l|c|c|}
\hline Subject & No. & $\mathbf{\%}$ \\
\hline Medical geography title topics & 13 & $23.6 \%$ \\
\hline Geography of Disease & 13 & $23.6 \%$ \\
\hline Health and disease environment & 7 & $12.7 \%$ \\
\hline Geographical distribution of health services & 4 & 7.3 \\
\hline Cause of death and mortality & 4 & 7.3 \\
\hline Health and development & 3 & 5.5 \\
\hline Behavioral dimensions & 2 & 3.6 \\
\hline Historical geography of disease & 2 & 3.6 \\
\hline Climatic change & 2 & 3.6 \\
\hline Disease diffusion & 2 & 3.6 \\
\hline Disease mapping & 2 & 3.6 \\
\hline Treatment recreation & 1 & 1.8 \\
\hline Total & $\mathbf{5 5}$ & $\mathbf{1 0 0}$ \\
\hline
\end{tabular}

The first collection which carries the title of Medical Geography is either applied studies in governorates or districts, or through textbooks. The number of these studies is 13 with the percent of $23.6 \%$. These studies is started with the first unpublished M.A thesis discussed in Egypt 1986 in Minia University by Elsabawy, M.N about "Medical Geography: An applied study in Kafr Elsheikh 
Governorate". The second study is an unpublished M.A thesis 1987 in Zagazig University about "Geography of health in Kuwait country". The third study is an unpublished M.A thesis 1989 in Zagazig University too about "Medical Geography for Elsharkiah Governorate" .The fourth study is an unpublished Ph.D. dissertation in 1993 in Minia University by Elsabawy,M.N. about " health Problems of population of Minia Governorate :A study in medical Geography.". The fifth study is an unpublished Ph.D. dissertation in 1995 by Elgazairly in Alexandria University with the title of " Alexandria Governorate: A study in medical geography" In the same year, Emad Eltemamy introduces his unpublished Ph.D. dissertation about "Medical geography to Kinia".

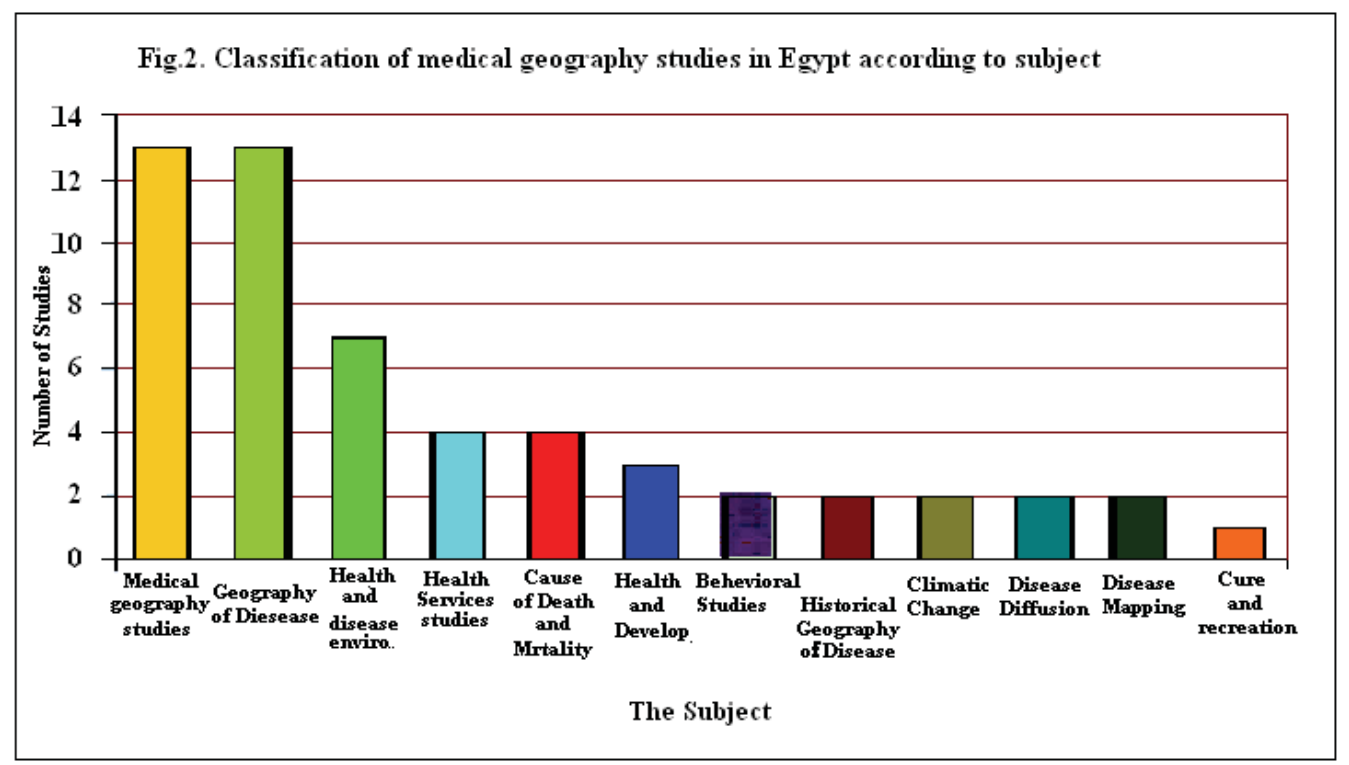

The Seventh study is an unpublished M.A thesis in 1995 in Cairo University by Afaf Sayed Mohamed under the title of "Medical geography for Elkalubia Governorate". The eighth study is a text book for Elsabawy, M.N., 1996 under the title of "Medical Geography: techniques and field studies". The ninth paper is a published in 1997 for Gaber,M.M., under the title of "medical geography for the Africa continent". The tenth paper is in 1998 for Mohamed,K.H., about "new directions in medical geography". The eleventh unpublished Ph.D.thesis in 2000 for Hoida Ramadan about "Kafr Eldawar district : A study in medical geography. The twelfth unpublished M.A. thesis is in 2004 for Sahar Elziny about "Elmahala Alkobra district: A study in medical geography". And the last textbook is in the same year for Gaber.M.M\&Faten Elbana, about " studies in medical geography".

The second collection correlates with geography of disease, the number of studies in this field is "13" studies, with the percent of $23.6 \%$., the first study is paper for Gaber, M.M., in 1988 about "Cancer in the Arabian Gulf countries: A study in Medical Geography,". The second paper for the same author is in 1992 about "Geographical Environment as A Carcinogenesis in some Arab countries: A study in Medical Geography". The third paper is for Faten Elbana in 1992 about " geographical dimensions to AIDS Disease in Afrrica continent". The fourth study is a paper in 1997 by Elgazairly about "Geographic dimension to bilharsiasis disease in egyptian governorates". The fifth paper in 1998 is for Mohamed Abdelghany Saudi about "AIDS in Africa:A study in medical geography". The sixth study is a textbook for Gaber, M.M., in 1999 about "Geographical dimensions for Aids Disease: A study in Medical geography". The seventh study is a paper for Gaber, M.M., about" geographical analysis for genetic disease in the Arab world". The eightieth study is a paper in 2002 for Elsabawy,M.N., about "geographical dimensions of malaria and sickle cell Anemia:A 
study in medical geography". In the same year, Yara Abdelhamid registered an M.A. thesis in Minia University about "Cancer disease in upper Egypt: geographical analysis". The tenth study is a registered M.A. thesis in Minia University 2004 for Zenab Abdelhakem about "liver Diseases in Egypt: A study in medical geography". The eleventh is an PH.D registered in Tanta university 2006 for Sahar Elzeny about "Cancer in Elghrbia governorates: A study in medical geography with GIS Technique ".The twelfth unpublished M.A. thesis is in Minia University 2006 for Mohamed Abdelrazek about "Kidney failure disease in Suhag governorate: A study in medical Geography, The last paper in 2006 is for Mohamed Abdu Badr Eldin about "geographical analysis for liver diseases in Egypt".

We can see that this category is covering a wide range of study of disease, not only on the range of Egypt level, but also in the Arab world ,Africa continent, and the whole world.

The third collection is about Health and disease environment, the number of these studies is 7 with percent $12.7 \%$. The first one is a text book published in 1986 by Abd-Elaziz Torayah Sharaf about "Environment and human health in medical geography". Another study is a paper published in 1995 by Nawal hamed about "Diseases and the environment in Abha and Minia Elkamh: comparative geographical study" The third study is an M.A thesis registered in Minia University in 2002 by Mohamed Salaheldin about" Health and Disease in south Sinai Governorate". The fourth study is a paper published in 2006 by Elsabawy, M.N., about "unhealthy using roofs: $A$ study in health Ecology". The fifth study is a paper published in 2007 to the same author about "Toward health strategy to protect reclamation areas from infectious diseases". The sixth study is a paper published in 2007 by the same author, about "Geographic and health dimensions to labour rural women in the urban markets". The last study in this classification is a paper published in 2007 by Mohamed Abdelfatah about "Geographical factors on the disease environment in Kafrelsheikh Governorate" .

The fourth collection is about, Geographical distribution of health services. The number of these studies is 4 with percent $7.3 \%$. The first study is an unpublished Ph.D. dissertation in 1992 introduced to Ain Shams University by Fathy Bilal about "Cairo hospitals: a study in geography of services". The second study is an unpublished M.A thesis in 1995 introduced to Ain Shams University too by Nagat ismael about "Health services in united Arab Emirates". The third study is an unpublished Ph.D. dissertation in 1996 by Khalaf Allah Hasan about "Governmental health services in Assuit Governorate" :A study in medical geography". The last study is an published paper in 2001 by Elgazairly about " Geographical sphere of Mansura university hospitals".

The number of papers in fifth collection which is called "Cause of death" is 4 papers and studies only with the percent of $7.3 \%$ of all papers and studies. The first one of these papers is the first paper in medical geography by Abu Aiana "Some aspects of infant mortality in Alexandria Egypt: A study in Medical Geography". The second study is an M.A thesis registered in 2004 in Beni suif University by Taghrid Sayed about "Cause of death in Egypt in the twentieth century: $A$ study in medical geography". The third study in this group is an M.A thesis registered in 2006 in Minia University by Amro Abdelfatah about "Cause of death in Minia governorate in the twentieth century: A study in medical geography". The last study is an unpublished master thesis. In Minia University 2006 for Reda Aly about" Demographic and Epidemiological transition in Beni-suif governorate in twentieth century".

In the same hierarchy "Health and Development", there are three studies in this field. The first one in 1994 is by Faten Elbana, about "health care and human development in Africa".The second study to the same author is in 1995 about "Geographic analysis for some development and settlements projects in Africa: with special reference to effect in health ". The last study is in 2003 by Gaber, M.M., about "Geographyical, Biological, Cultural determinants to health sustainable in Africa".

The study of disease diffusion, behavioral dimensions, climatic change, and historical medical geography have the same percentage of $3.6 \%$ eash category has 2 studies only. The first is a paper published in 1988 by Gaber, M.M., about" Migration, Mobility and disease diffusion with 
special reference to the situation in the Arabian Gulf countries: A study in Medical Geography. Another study is about disease diffusion in 1997 by Elsabawy, M.N., about "The impact of Roads and routes in the diffusion of diseases: Geographical studies", the study is conducted within historical perspective. The theory of diffusion is studied by Faten Elbana through "The diffusion process: theory and practice" in 2002.

The second topic "Behavioral dimensions in the study of Medical Geography", is studied through some papers and textbooks, one of them is published in 2004 by Elsabawy,M.N. about "Child Abuse: A study in behavioral Geography. The second paper to the same author about "Behavioral Dimensions in the study of medical geography: An applied study in tokh Elkhail in village, Minia Province".

Climate changes too is studied in 2000 by Gaber,M.M., through paper about "Health Consequences of "El Nino,. Another study to the same author also in 2000 is about" Climate change and its effects on health and development with a special reference to Africa continent".

Historical geography of disease is the purpose of study through this paper which published in 2007 by I brahim Eldusuky about "geographical dimensions for plague epidemic in Egypt".

One of studies in disease mapping is an unpublished M.A. thesis in 2003 to Monufia University by Sobhy Abdelmageed, about "Occupational map diseases in Quisna province: a geographic study". Another study is a paper published in 2000 by Gaber.M.M., about "G/S applications and remote sensing in the field of medical geography".

Another paper about recreation treatment is studied by Fatma Abd Elsamad, under the title of " Geographical dimensions of recreation treatment in Egypt". Published as special issue in the Bulletin of Egyptian geographical Society in 2006.

We can see from this view that there are variant studies covered Egypt and some governorates. Clearly we can decide that the studies of medical geography in Egypt seem to be more general and more comprehensive. But there is no strategic plan to study topics related to health problems of every governorate separetly, through geography Departments in the universities of Egypt, in order to draw a map of health level on the regional or national scale. Through cooperation between the universities and the ministry of health support or World Health Organization It may be possible to make this step.

\subsection{The range of study zones}

Medical geography studies in Egypt are covering a wide range from the world scale to a small village in Egypt; "from macro to micro" we can notice through the view of studies and papers in previous pages this variety and multiple locations of study which are covering all spatial levels. Table (3) and figure(3) show the number of studies, there are 7 studies with percent 12,7\% covered the world level, and 8 studies to Africa continent with percent $14.6 \%$, the studies of Arab world is 4 only with percent $7.2 \%$. But on the level of Egypt as a whole there are 11 studies with percent $20 \%$, this is the high percent, if we add all these studies we find it 30 studies, with percent $54 \%$ in the medical geography study in Egypt covered the world, the Arab world and Egypt. We can say that this is an indicator to generalization in the study of medical geography, and this is a logical result because the study of this branch in the first and second decades from the study of medical geography in Egypt was still in born and when it reached to maturation stage we see specific studies in micro study. Studies which covered governorates, provinces and rural areas are 16 with percent 29\% covered Egyptian governorates, provinces and rural areas, and there are 9 studies with percent $16.4 \%$ are not classified into any location, as general studies.

Table 3: Classification of medical geography studies in Egypt according to the region of study

\begin{tabular}{|l|c|c|}
\hline Region of study & No. of studies & $\mathbf{\%}$ \\
\hline Studies on the world level & 7 & $\mathbf{1 2 . 7 \%}$ \\
\hline
\end{tabular}




\begin{tabular}{|l|c|c|}
\hline Studies on the African continent level & 8 & $\mathbf{1 4 . 6 \%}$ \\
\hline Arab world studies & 4 & $\mathbf{7 . 2 \%}$ \\
\hline Egypt or regions of Egypt studies & 11 & $\mathbf{2 0 \%}$ \\
\hline Egyptian governorates studies & 9 & $\mathbf{1 6 . 4 \%}$ \\
\hline Provinces or centers studies & 5 & $\mathbf{9 . 1 \%}$ \\
\hline Village level studies & 2 & $\mathbf{2 . 6 \%}$ \\
\hline General studies not related to any site & 9 & $\mathbf{1 6 . 4 \%}$ \\
\hline Total & $\mathbf{5 5}$ & $\mathbf{1 0 0}$ \\
\hline
\end{tabular}

\subsection{Susceptible Egyptian Governorates}

Studies of medical geography covered a number of Egyptian governorates, except some of them like Canal, Aswan, Matrouh, Giza, North Sinai. Some of studies are on the level of whole governorate and some of them cover parts of this governorates either centers or rural areas. We can notice that two governorates only are on the top of purpose studies, Elminia and Kafr Elshikh have 3 studies, Sharkia governorate is in the second, with two studies, and every other governorate has one study only. Table(4). Fig.(4)

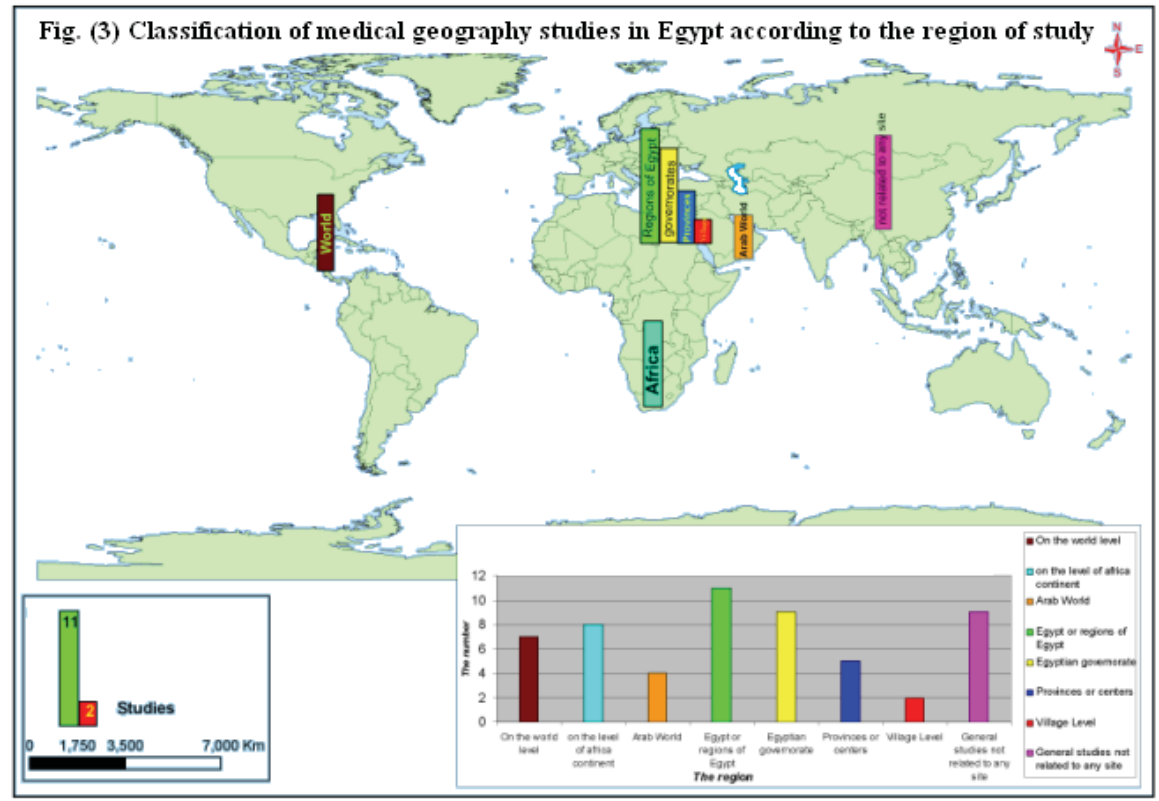

Table 4: Classification of medical geography studies according to number of studies in Egyptian Governorates

\begin{tabular}{|l|c|c|}
\hline Egyptian governorates which studied & $\begin{array}{c}\text { On the level } \\
\text { governorates }\end{array}$ & $\begin{array}{c}\text { On the level of parts } \\
\text { of governorates }\end{array}$ \\
\hline Kafr Elshikh Governorate & 2 & 1 \\
\hline Alexandria Governorate & 1 & \\
\hline Kalubia Governorate & 1 & 1 \\
\hline Sharkia Governorate & 1 & 1 \\
\hline Minia Governorate & 2 & \\
\hline Beni Suif Governorate & 1 & \\
\hline
\end{tabular}




\begin{tabular}{|l|c|c|}
\hline Assuit Governorate & 1 & \\
\hline Suhag Governorate & 1 & 1 \\
\hline Gharbia governorate & & 1 \\
\hline Behira governorate & & 1 \\
\hline Dakahlia governorate & 1 & \\
\hline South Sinai & $\mathbf{1 1}$ & $\mathbf{6}$ \\
\hline Total & & \\
\hline
\end{tabular}

\subsection{Universities participation in Egypt}

The interest in medical geography studies in Egypt started in the geography departments in regional Universities, not in the mother Universities, like Cairo, Ain-shams, and Alexandria. This interest of medical geography studies in Egypt was born in the womb of geography department, Minia University, this department is not only interested in this branch only but also in some new directions of geography like Behavioral Geography, Geography of Crime, and language geography.

Table (5) and Figure (5) show up how Geography department in Minia University is on the top of the Egyptian geography departments in the number of medical geographical theses M.A or PH.D. degrees, the percent of studies in Elminia is $45.5 \%$, from the total number of thesis and dissertations in medical geography, Cairo Alexandria, Zagazig, Tanta, and Ain Shams in the second with $9.1 \%$ to each, other universities Beni Suif , and monufia about $4.5 \%$.

Fig. (4) Classification of medical geography studies according to number of studies in the Egyptian Governorates

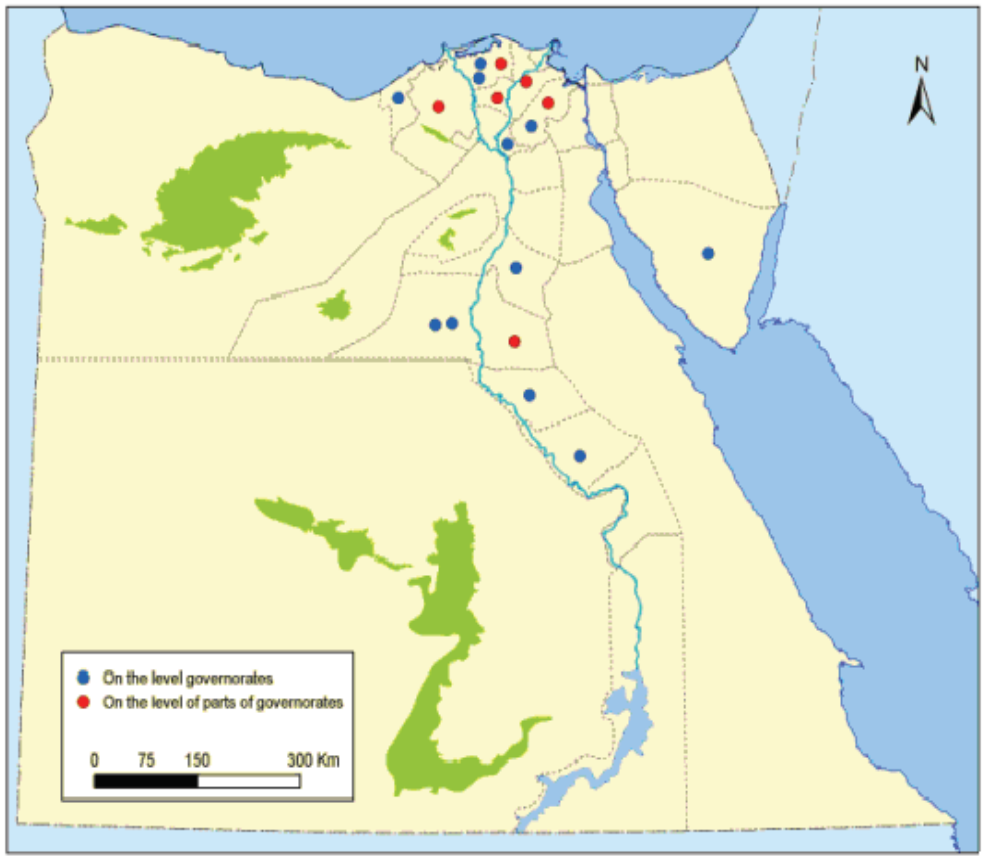


Table 5: Classification of medical geography studies according to Number of studies in the universities

\begin{tabular}{|l|c|c|}
\hline Egyptian Governorates & The number & $\mathbf{\%}$ \\
\hline Minia University & 10 & 45.5 \\
\hline Alexandria University & 2 & 9.1 \\
\hline Zagazig University & 2 & 9.1 \\
\hline Tanta University & 2 & 9.1 \\
\hline Cairo University & 2 & 9.1 \\
\hline Ain Shams University & 2 & 10 \\
\hline Beni Suif University & 1 & 4.5 \\
\hline Monufia University & 1 & 4.5 \\
\hline Total & $\mathbf{2 2}$ & $\mathbf{1 0 0}$ \\
\hline
\end{tabular}

Fig. (5) Classification of medical geography studies according to Number of studies in the Egyptian universities

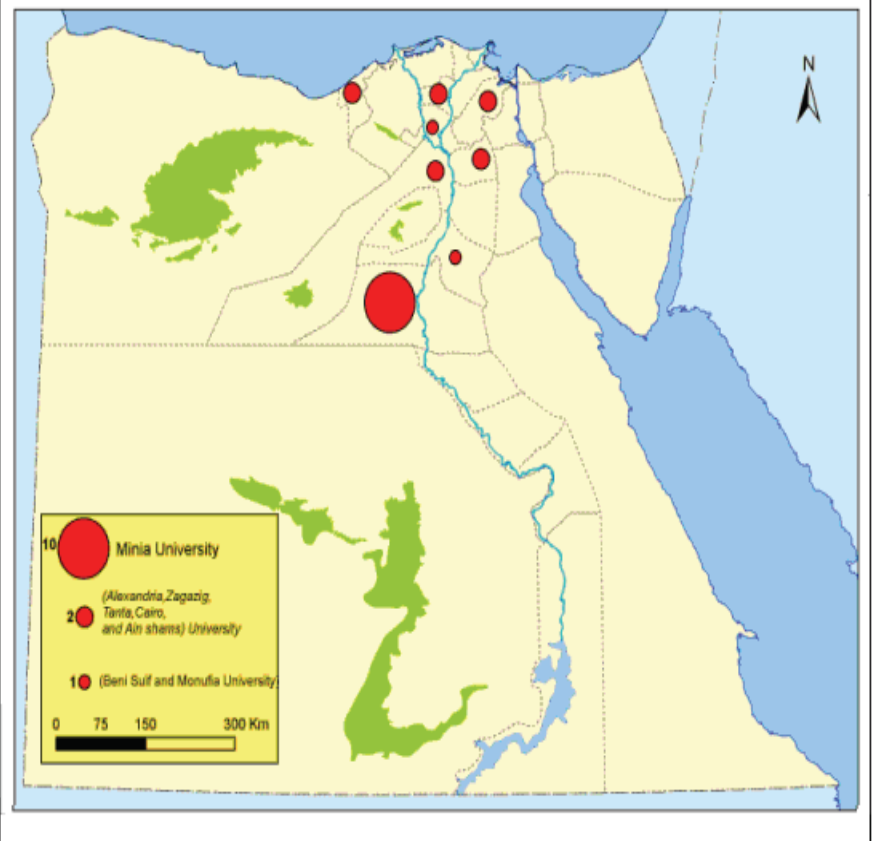

\subsection{Publishing type}

We can divide all studies in medical geography according to publication to 5 categories as shown in table 6 and figure 6.

We notice that there are $34.5 \%$ from studies in medical geography are M.A. and PH.D. theses, the second is papers and articles which are published in the journals of universities faculties, and in third importance these papers which published in the journal of Egyptian geographic Society, and in the same percent these papers and studies which are shared in the conferences and committees, and then textbooks $9.1 \%$ 
Table 6: Classification of medical geography studies according to Scientific publishing

\begin{tabular}{|l|c|c|}
\hline Scientific publishing & Number & $\mathbf{\%}$ \\
\hline Master and PH.D Degrees & 19 & 34.5 \\
\hline Papers published in the college journals & 15 & 27.3 \\
\hline Articles published in Egyptian geographical society & 8 & 14.5 \\
\hline Papers published in conferences and committee & 8 & 14.5 \\
\hline textbooks & 5 & 9.1 \\
\hline Total & $\mathbf{5 5}$ & $\mathbf{1 0 0}$ \\
\hline
\end{tabular}

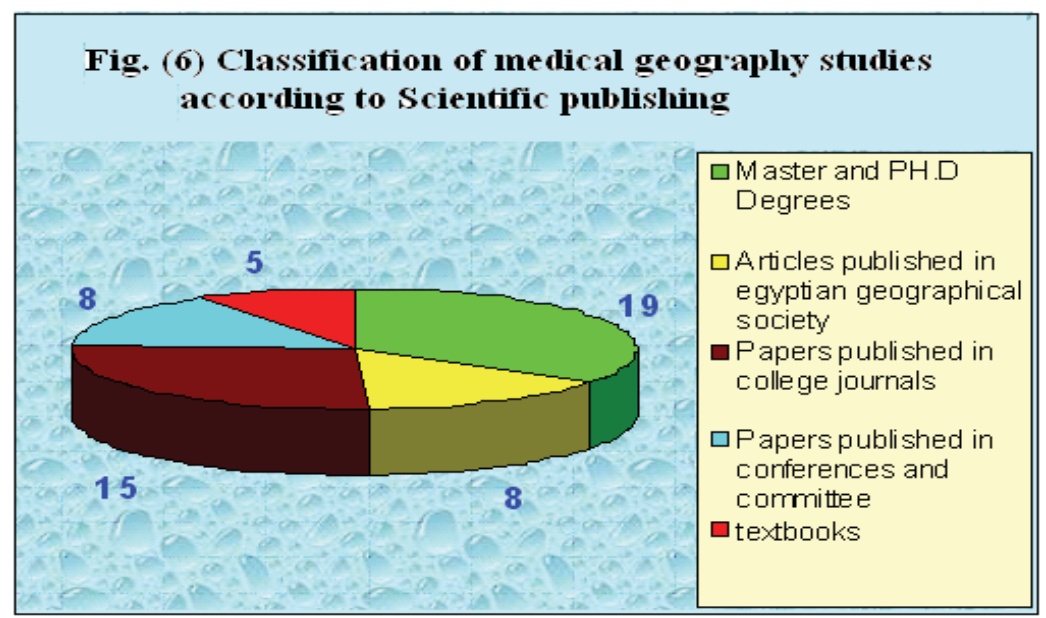

\subsection{Specialists in Medical Geography}

All researchers and students are sharing in medical geography papers and studies reached to 28 during 30 years from 1979 -2008. The average of studies or study for each one researcher is 0.51 paper. This is a small number and a small production too. The percentage of researchers who write papers in this field, and not specialized, is $15.3 \%,{ }^{2}$.

Wherever the number of researchers who wrote in medical geography and they registered or obtained M.A Degree is 12 with the percentage of $20.3 \%$, the number of researchers who wrote in medical geography and they registered or obtained Ph.D. Degree is 8 with the percentage of $13.6 \%$, but the number of specialists in medical geography is only two, with percentage $3.4 \%$, as shown as table (7) and figure (7)

Table 7: Classification of researchers and Specialists in medical geography

\begin{tabular}{|l|c|c|}
\hline Species of students in medical geography & No. & $\%$ \\
\hline Total of researchers and specialists who wrote in medical G. & 28 & 47.5 \\
\hline Who wrote, not obtained Master or Ph.D. degree in Medical G & 9 & 15.3 \\
\hline students, obtained or registered Master degree in M. Geography & 12 & 20.3 \\
\hline students, obtained or registered Ph.D. degree in M. Geography & 8 & 13.6 \\
\hline Specialists in medical Geography MA+Ph.D & 2 & 3.4 \\
\hline Total & 59 & 100 \\
\hline
\end{tabular}

\footnotetext{
2 I consider that any researcher who has not obtained or registered M.A. Degree and Ph.D. Degree in Medical Geography is not specialist in Medical Geography
} 
We can see that the number of specialists in medical geography in Egypt is very insignificant, and the number of all researchers and students is small, although thirty years have passed since the first study appeared in 1979. On the other hand, we can find that some names are repeatedly in this field through the number of studies and papers, these names is 4 only, with percent of $7.2 \%$, they study about 27 papers and studies in this field, with the percentage of $49,1 \%$ in total papers, as shown in table (8) and figure (8)

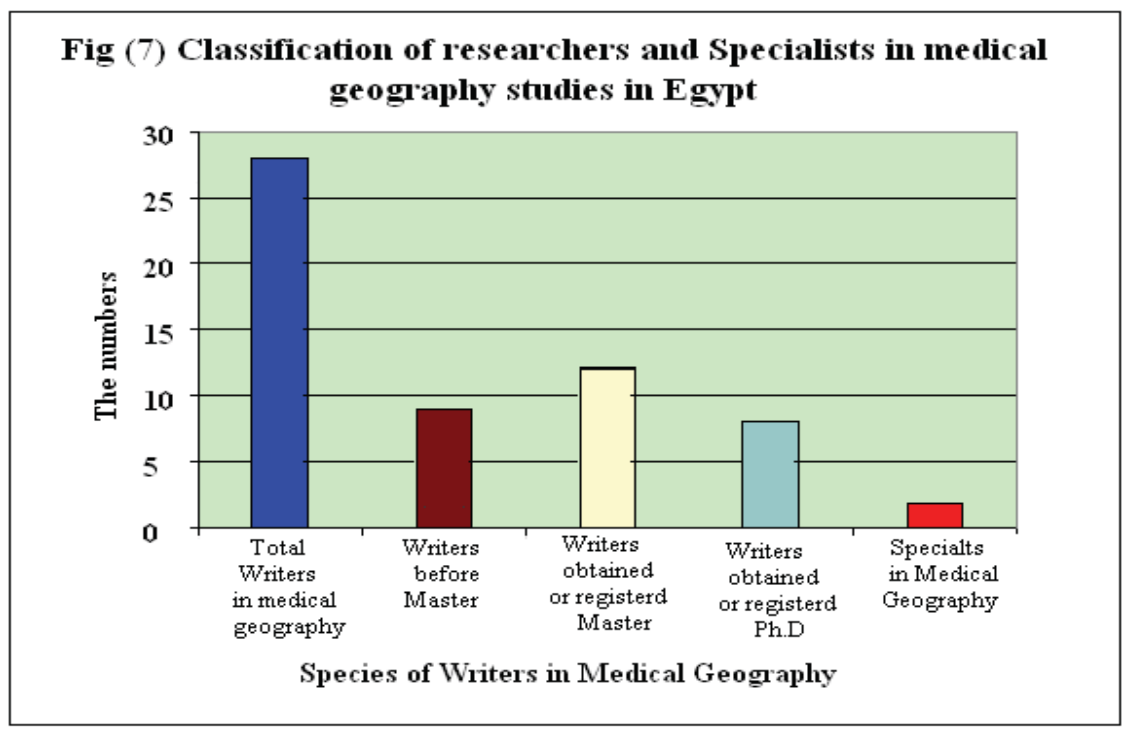

Table 8: Papers which more repeatedly

\begin{tabular}{|l|c|c|}
\hline Names & No. & \% \\
\hline Mohamed Medhat Gaber & 10 & 18.2 \\
\hline Mohamed Nour Eldin Elsabawy & 10 & 18.2 \\
\hline Faten Elbanna & 4 & 7.3 \\
\hline Abd Elhameed Elgazairely & 3 & 5.5 \\
\hline Total & $\mathbf{2 7}$ & $\mathbf{4 9 . 1}$ \\
\hline
\end{tabular}

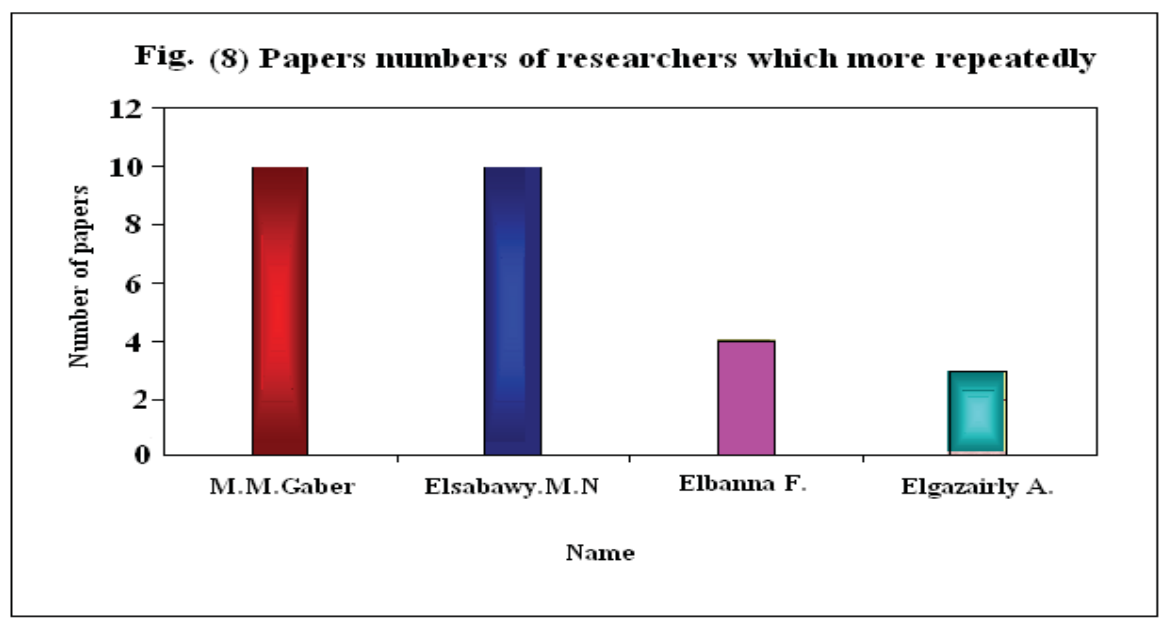




\section{Conclusion}

Medical geography as an interdisciplinary sub-discipline or subfield in Human and Social geography is important because it aims to provide spatial understanding of health problems and improving health care systems worldwide. It is succeeded to put its foot on the geographic departments in Egyptian universities after became a learning subject in undergraduate and postgraduate courses in many universities in Egypt. Despite that has been emerged late in Egypt, compared to developed countries, it has found a good place among other geographic branches in a few years.

Its depending upon many systems, polices and Sciences e.g. medicine, engineering, soil, Geology, Biology, Economy, Politics, History, and psychology. Etc. The main approaches of medical geography depends upon many trends and attitudes like disease diffusion, disease pattern, health care services, ethno medicine and medical pluralism, nutritional geography, disease mapping, and associative relations.

Medical geography studies in Egypt started by geographers in 1979. We cannot neglect the contributions of physicians and scientists in the medical studies in this field in Egypt before this time, which help geographers in their studies and papers. After this date, geographical studies are developed by geographers but slowly, either in numbers or in the topics nature. Gradually this development becomes necessary, because the concept, terrain, and the range of this subfield were not understandable in the first studies. So Many researchers preferred choosing general topics at first. Gradually, they have been concentrating, deliberating on subjects related to some diseases which refer to Egyptian geographical environment. Explicitly.

This study attempted to follow up, analyze and classify studies of Medical geography in Egypt, since the existence of that branch in the beginning of 1980s to 2010, to observe the development of these studies. We can decide that the studies of medical geography in Egypt seem to be more general and more comprehensive firstly. But in the second and third decade from beginning of study it was more specific and concentrated, the general trend of papers studied problems of peoples like liver diseases, Kidney failure, respiratory, cancer, malaria, cardiovascular in Egypt or on the narrow scale.

There is no strategic plan to study topics related to health problems of every governorate separetly, through geography Departments in the universities of Egypt, in order to draw a map of health level on the regional or national scale, may be through co-operation between the universities and the ministry of health support, or World Health Organization It would be possible to make this step. This study suggests finding topics in medical geography in the university, to study health problems in Egypt in geographical view, through co-operation between ministry of health and universities can draw a health or disease map to each governorate. These studies can help decision makers and policies actors through strategic plan to eradicate serious diseases in Egypt.

\section{References}

Gesler., W. M. ., Therapeutic landscapes: Medical issues in light of the new cultural geography., Social Science \& Medicine ., Volume 34, Issue 7, Pages 735-746, April 1992.

Hall, S. A. and Langlands, B. W.: Atlas of disease distribution in Uganda. Nairobi, East Africa Publishing House, 1975.

Hartwig, S. W. and Patterson, K. D. (ed.): Disease in African history. Durham N. C. Duke U. P. 1978

Hughes, C. C. and Hunter, J. M.: Disease and development in Africa: the continuing need for an ecological approach. Soc. Sci. and Med. 3, 443-493 (1970)

Hunter, J. M.: River blindness in Nangodi, northern Ghana: a hypothesis of cyclical advance and retreat. Geographical Review 56, 398-416 (1966)

Hunter J.M., The challenge of medical geography, In J.M. Hunter (ed), The Geography of Health and Disease, Studies in Geography series no. 6, Dept. of Geography, University of North Carolina at Chapel Hill, pp.1-31. (1974). 
Hunter, J. M. (ed.): The geography of health and disease. Studies in Geography No. 6.Department of Geography, University of North Carolina at Chapel Hill (1976)

Kloos, H. and Thompson, K.: Schistosomiasis in Africa: an ecological perspective. J. Tropical Geography 48, 31-46 (1979)

Knight, C. G.: The ecology of sleeping sickness in Africa. Annals Ass. American Geographers 61, 23-44 (1971)

Learmonth, A. T. A.: Patterns of disease and hunger. Newton Abbott, David and Charles (1978).

Mayer J. D. "Special Issue: New Directions in Medical Geography" Social Science \& Medicine. Part D: Medical Geography ., Volume 13, Issue 4, , Pages 267-271 December 1979. Available online 2 July 2002.

McGlashan, N. D.: Measles, malnutrition and blindness in Luapula Province, Zambia. Trop. Geogr. Med. 21, 157-162 (1969 a)

McGlashan, N. D.: The African lymphoma in Central Africa. Int. J. Cancer 4, 113-120 (1969 b)

McGlashan, N. D. (ed.): Medical geography: techniques and field studies. London, Methuen (1972)

McGlashan, N. D. and Rose, E. F.: The spatial distribution of oesophageal carcinoma in the Transkei, South Africa. Int. J. Cancer 31, 197-206 (1975)

May, J .: Various world maps of the distribution of diseases in the Geographical Review. Missing Date.

Nash, T. A. M.: The Anchan rural development and settlement scheme. London, His Majesty's Stationary Office for the Colonial Office (1948).

Prothero, R. M.: Population movements and problems of malaria eradication in Africa. Bull. World HIth. Org. 24, 405-425 (1961)

Prothero, R. M.: Population mobility and trypanosomiasis in Africa. Bull. World HIth. Org. 28, 615-626., (1963)

Prothero, R. M.: Disease and human mobility: a neglected factor in epidemiology. International J ournal of Epidemiology 6, 259-267 (1977)

Pyle, G. F. (ed.): Special issue on Medical Geography. Economic Geography 52 (1976)

Pyle, G. F.: New directions in medical geography. Soc. Sci. and Med. 13D, 205-207 (1979)

Pyle, G. F.: Applied Medical Geography. Winston, Washington 1979.

Pyle G.F Medical geography in the United States, In N.D. McGlashan and J.R. Blunden (eds), Geographical Aspects of Health, Academic Press, London, p.83. . (1983), 
